\title{
Gastrointestinal cancers, ACE-2/TMPRSS2 expression and susceptibility to COVID-19
}

\author{
Sepehr Shafiee ${ }^{1}$, Luca Cegolon², Mostafa Khafaei ${ }^{3}$, Nasrin Gholami ${ }^{4}$, Shi Zhao ${ }^{5}$, Nasrin Khalesi ${ }^{6}$, \\ Hamidreza Moosavian ${ }^{7}$, Saeid Fathi ${ }^{8}$, Morteza Izadi ${ }^{9}$, Alireza Ghadian ${ }^{10}$, Mohammad Javanbakht ${ }^{10^{*}} \mathbb{D}$, \\ Amin Javanbakht ${ }^{11}$ and Reza Akhavan-Sigari ${ }^{12}$
}

\begin{abstract}
Recent studies on the pathophysiology of COVID-19 are indicating that the Angiotensin convertase enzyme 2 (ACE-2) and transmembrane serine protease 2 (TMPRSS2) can act as a major component in the fusion of SARS-Cov-2 with target cells. It has also been observed that the expression of ACE-2 and TMPRSS2 can be altered in malignancies. Shedding light on this matter could be crucial since the COVID-19 pandemic interfered with many gastrointestinal cancer screening programs. Herein we discuss the possibility of severe forms of COVID-19 in patients with gastrointestinal cancers due to the gastrointestinal entry route of SARS-CoV-2 into the human body. The disruption of cancer screening programs caused by the current COVID-19 pandemic could therefore have massive negative health impact on patients affected by gastrointestinal malignancies.
\end{abstract}

Keywords: Gastrointestinal cancer, COVID-19, Angiotensin convertase enzyme 2, transmembrane serine protease 2, Pathophysiology

\section{Background}

In 2020, the COVID-19 pandemic challenged the healthcare systems of more than 200 countries, resulting in the death of more than 1.5 million people worldwide [1]. In several countries, the exponential surges in the number of COVID-19 cases during the second and third wave of the pandemic resulted in healthcare systems reaching their capacity [2]. The shortage of medical supplies and healthcare resources, occupation of hospital wards and increased risk of nosocomial COVID-19 infections interfered with many medical procedures such as elective surgeries, screening for cancer and even vaccinations [3]. Albeit several commercial COVID-19 vaccines are currently available, achieving herd immunity through vaccination is still a debated endpoint. With that in mind,

\footnotetext{
*Correspondence: mhmjvbt81@gmail.com

${ }^{10}$ Nephrology and Urology Research Center, Baqiyatallah University of Medical Sciences, Tehran, Iran

Full list of author information is available at the end of the article
}

several vaccination guidelines have been developed to prioritize sub-groups vulnerable to COVID-19 [4, 5]. Arranging these guidelines require deep knowledge of the COVID-19 pathophysiology, which is continuously evolving.

Whilst initial studies focused on respiratory symptoms of COVID-19, latest evidence suggested that gastrointestinal (GI) symptoms are usual and SARS-CoV-2 can be detected in feces in about $50 \%$ of infected subjects, although no clear association between GI symptoms and SASR-CoV-2 positivity of feces exists yet [6]. The most common GI symptoms include nausea, anorexia, diarrhea and vomiting and are associated with severe forms of the disease, extended hospitalizations and higher mortality risk [6-9]. Furthermore, it has been observed that SARS-CoV-2 could be isolated from stool samples even after testing negative for COVID-19 in the upper respiratory tract [10]. Several mechanisms have been proposed to explain the underlying causes of the GI symptoms associated with COVID-19, including disturbance of original author(s) and the source, provide a link to the Creative Commons licence, and indicate if changes were made. The images or other third party material in this article are included in the article's Creative Commons licence, unless indicated otherwise in a credit line to the material. If material is not included in the article's Creative Commons licence and your intended use is not permitted by statutory regulation or exceeds the permitted use, you will need to obtain permission directly from the copyright holder. To view a copy of this licence, visit http://creativecommons.org/licenses/by/4.0/. The Creative Commons Public Domain Dedication waiver (http://creativeco mmons.org/publicdomain/zero/1.0/) applies to the data made available in this article, unless otherwise stated in a credit line to the data. 
GI flora, drugs side effects and most importantly direct infection of enterocytes [11]. Novel evidence in fact suggests that SARS-CoV-2 can invade the enterocytes, where it can replicate and spread through fecal-oral transmission route $[12,13]$. Understanding the underlying mechanism of direct invasion of the GI tract by SARS-CoV-2 could therefore help predict the conditions potentially influencing the clinical pattern of COVID-19.

In the early days of the pandemic, the imperfect risk assessment of COVID-19 postponed several preventative schemes as GI cancers screening programs due to the unknown nature and behavior of SARS-CoV-2, which initially was believed to be capable of invading only the lung parenchyma.

Herein, we discuss how malignant transformation can make patients with GI tumors more susceptible to direct invasion by SARS-CoV-2 and more vulnerable to severe forms of COVID-19, thus questioning the rationale of discontinuing cancer screening programs, especially against GI cancers.

\section{Discussion}

\section{The role of ACE-2 and TMPRSS2 in SARS-CoV-2 cellular} invasion

Investigating the pathophysiology of COVID-19 and cellular pathways contributing to viral invasion, proliferation and immunogenicity not only supports the search for a cure against the disease but also helps stratifying the morbidity and mortality risk for COVID-19, defining susceptible sub-groups. One of the initial leading hypotheses of COVID-9 transmission was that SARS-CoV-2 invades target cells via the Angiotensin Converting Enzyme-2 (ACE-2) receptor [14] (Fig. 1).

ACE-2 is a single-pass type 1 membrane-bound enzyme of several epithelial lineage cells of various tissues, including the lung, GI tract, liver, kidney and brain. The latter X-linked enzyme, which is bound to a Zinc ion, consists of an extracellular enzymatic domain, a transmembrane chain and an intracellular C-terminal portion [15]. ACE-2, an important part of the renin-angiotensin system, is not only known for its role in regulating blood pressure by hydrolyzing and turning Angiotensin 2 into Angiotensin (1-7), but it also contributes to many physiological processes such as inflammation, tissue development and neuro-degeneration [16]. In the reninangiotensin system ACE-2 downregulates ACE. Whilst Angiotensin 2 binds with AT1 receptor to induce vasoconstriction, inflammation and fibrosis, Angiotensin (1-7) acts on Mas receptors (MasR) inducing powerful vasodilation and anti-proliferative as well as anti-apoptotic action [17].

ACE-2 cell receptor was confirmed as the port of entry for SARS-CoV-1 into target cells [14-16, 18]. Since
SARS-CoV-1 and SARS-CoV-2 share a high degree of homology, ACE-2 was immediately indicted as the main potential entry route also of SARS-CoV-2 infection of target cells from the early stages of the COVID-19 pandemic [19]. As shown in Fig. 2, SARS-CoV-2 binds with target cells through its Spike $(\mathrm{S})$ protein, which is cleaved and primed by the host transmembrane serine protease 2 (TMPRSS2) and the disintegrin and metalloproteinase 17 ADAM17 [20, 21]. In addition to Spike proteins of SARS-CoV-1 and SARS-CoV-2, TMPRSS2 cleaves and activates also influenza virus hemagglutinin [22-24]. Co-expression of ACE-2 and TMPRSS2 could be the GI entry route for SARS-CoV-2 not only in pneumocytes but also in absorptive enterocytes of ileum and colon and may account for the frequent GI symptoms of COVID-19 $[6,25]$.

Severe forms of COVID-19 are seemingly triggered by an immunological imbalance leading to severe acute respiratory syndrome (SARS) and cytokine storm [26]. ACE-2 receptor has a vital function in the pathogenesis of COVID-19, activating the coagulation system (causing thrombophilia), the renin-angiotensin system (leading to cardiovascular instability) and the kinine-kallikrein system (causing acute inflammatory lung oedema) [27, 28]. Several manifestations of COVID-19, such as cardiovascular, kidney and brain symptoms, are associated with expression of ACE-2 and TMPRSS2 [29-31]. With that in mind, finding populations and conditions with upregulated expression of ACE- 2 could be useful to detect susceptible sub-groups for targeted prevention of severe forms of COVID-19.

Since elevated expressions of ACE- 2 and TMPRSS2 are associated with higher mortality risk from COVID-19, the latter two receptors have been investigated to develop potential agents effective to interfere with the replication of SARS-CoV-2 [32-34]. Targeting TMPRSS2 by a protease inhibitor could in fact be an anti-COVID-19 strategy blocking SARS-CoV-2 cell infection $[18,35]$.

\section{Expression of ACE-2 and TMPRSS2 in malignant transformation}

Expression of ACE-2 and TMPRSS2 in tumor cells may be remarkably different from normal tissue cells (Fig. 3).

ACE2 is highly expressed in various cancers including, squamous cell/adenosquamous carcinoma, endometrial carcinoma, colorectal, breast, prostate and lung cancer [36-38] as well as prostate adenocarcinoma [39].

Expression of ACE-2 and respective prognosis can be quite variable in different solid malignancies, depending on the stage and the underlying origin of the tumor [40]. The analysis of the Cancer Genome Atlas (TCGA) and public data revealed ACE-2 overexpression in many kinds of malignancies, including 


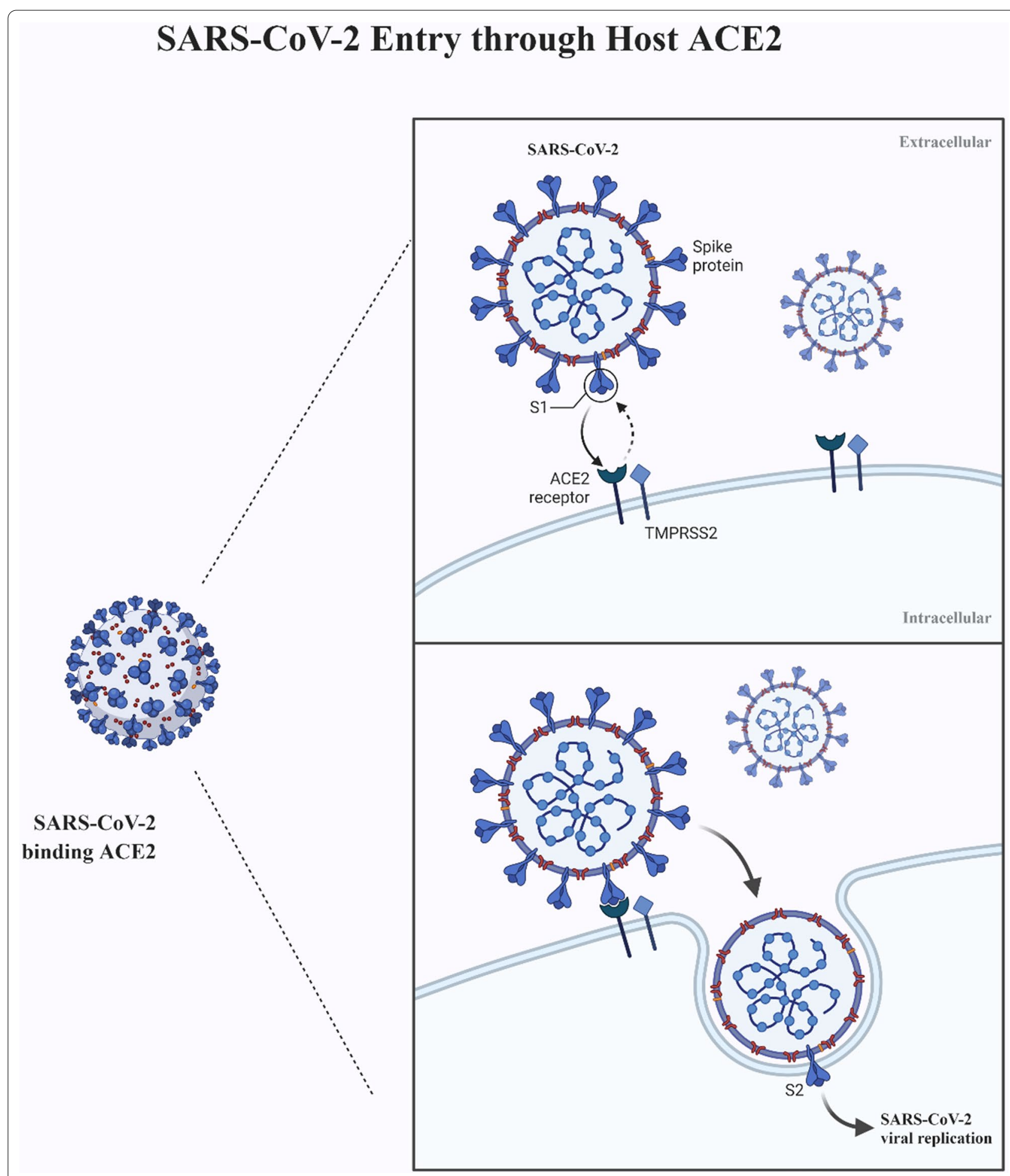

Fig. 1 The infection mechanism of SARS-CoV-2 through ACE-2 cell receptor

rectum adenocarcinoma, cervical cancer, pancreatic adenocarcinoma, kidney renal papillary cell carcinoma and kidney renal clear cell carcinoma, when compared with adjacent tissues, while ACE-2 downregulation was observed in liver, breast and prostate cancers [41]. By using the Oncomine and Tumor Immune Estimation 


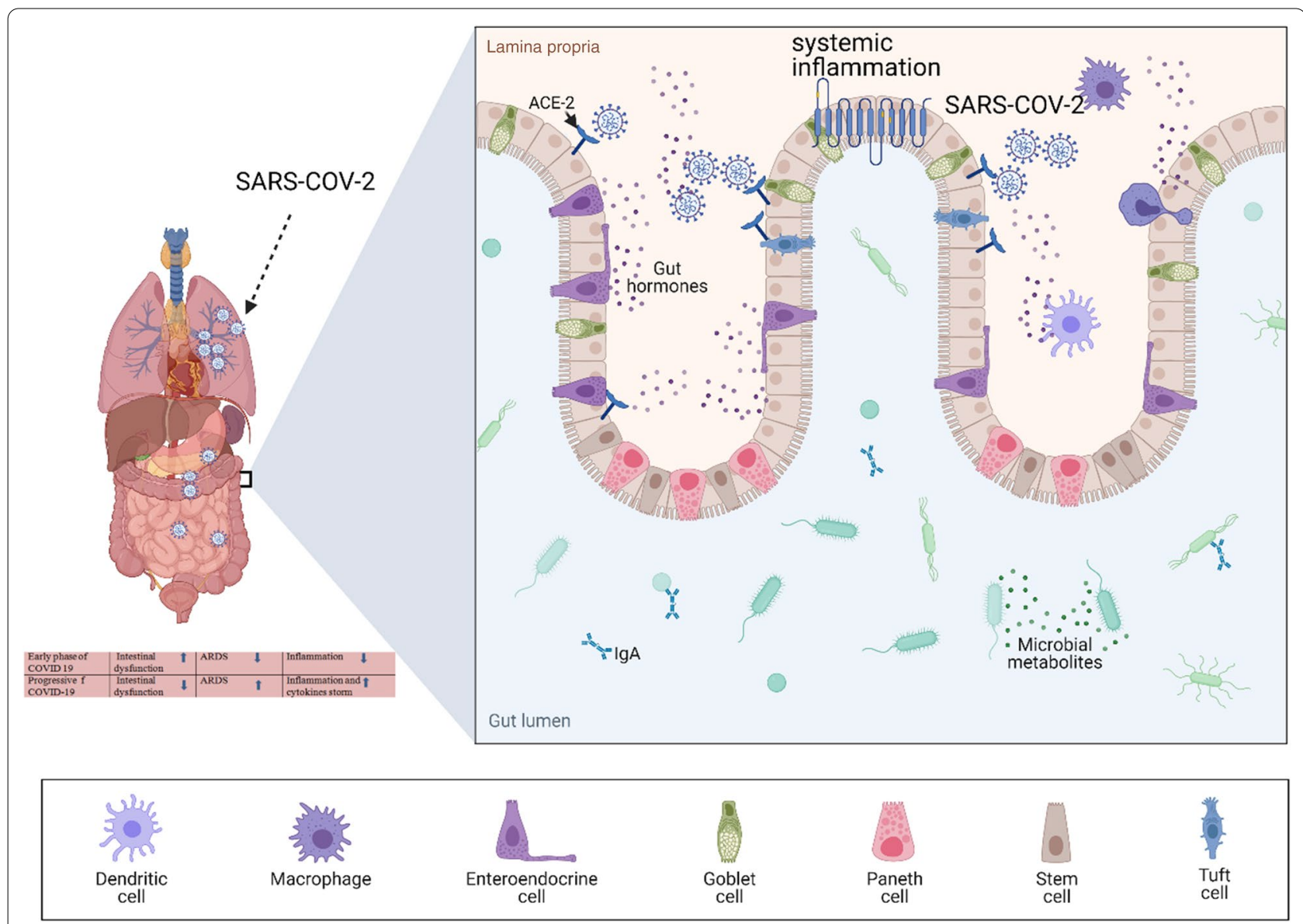

Fig. 2 SARS-COV-2 uses ACE-2 receptor to enter the absorptive enterocytes of the ileum and colon, causing the typical gastrointestinal symptoms of COVID-19

Resource (TIMER) databases, PrognoScan, GEPIA and Kaplan-Meier plotter databases, ACE-2 over-expression was found to be associated with higher overall survival in uterine corpus endometrial carcinoma (Hazard Ratio $=0.47$; 95\%CI: 0.30-0.73; Logrank $\mathrm{p}=0.0007)$, kidney renal papillary cell carcinoma (Hazard Ratio $=0.44$; 95\%CI: 0.24-0.81; Logrank $\mathrm{p}=0.0063)$, lung adenocarcinoma (Hazard Ratio $=0.60$; 95\%CI: 0.44-0.82; Logrank $\mathrm{p}=0.0011$ ) and liver hepatocellular carcinoma (Hazard Ratio $=0.55 ;$ 95\%CI: $0.38-0.80 ;$ Logrank $\mathrm{p}=0.0017$ ) [42]. The same study also reported a positive correlation between ACE-2 expression and level of immune infiltration by $B$ cells $\left(R^{2}=0.166 ; p<0.010\right), C D 4+T$ cells $\left(R^{2}=0.154 ; \mathrm{p}<0.010\right)$, neutrophils $\left(\mathrm{R}^{2}=0.223 ; \mathrm{p}<0.001\right)$ and dendritic cells $\left(R^{2}=0.271 ; p<0.001\right)$ in uterine corpus endometrial carcinoma. For kidney renal papillary cell carcinoma ACE-2 expression was positively correlated with degree of macrophage infiltration $\left(R^{2}=0.322\right.$, $\mathrm{p}<0.001$ ) [42]. Adjusting for tumor stage, presence of metastases, pathological state and histological grade, over-expression of ACE-2 was notably correlated with longer overall survival (Hazard Ratio $=0.8259$; 95\%CI: 0.7734-0.8819; Logrank $\mathrm{p}<0.0001)$ and relapse-free survival (Hazard Ratio $=0.8023$; 95\%CI: 0.7375-0.8729; Logrank $\mathrm{p}<0.0001$ ) in clear cell renal cell carcinoma patients, using TCGA, GEO and TIP database [43].

The expression of ACE-2 in cancerous cells has been subject to speculations, although ACE-2 upregulation seems to have a protective role against tumour progression, being associated with favorable prognosis [37, 38]. Whilst AT1 receptor promotes the angiogenesis by inducing VEGF production and uncontrolled cell proliferation of tumoral cells [44], the interaction of Angiotensin [1-7] with MasR inhibits genesis, abnormal proliferation and progression of tumors $[45,46]$.

Since it could disrupt the production of vascular endothelial growth factor (VEGF), interfering with angiogenesis and tumor growth, ACE-2 upregulation hindered migration and invasion of breast cancer cells both in vivo and in vitro [47]. Negative ACE-2 expression was in fact associated with poor prognosis at multivariable Cox analysis on 46 patients affected by squamous cell/ 
adenosquamous carcinoma of the gallbladder and 80 patients with adenocarcinoma of the gallbladder [48].

The activity of RAS oncogene, which influences cell proliferation and tumor growth, was upregulated in 19 patients affected by extrahepatic cholangiocarcinoma, resulting in significantly higher mean serum levels of ACE $(56.6 \pm 27.4 \mathrm{U} / \mathrm{l})$ as compared to patients with choledocolithiasis $(32.9 \pm 14.6 \mathrm{U} / \mathrm{l})$ and controls $(28.6 \pm 10.6$ U/l) [49]. ACE inhibitors have been studied as potential cancer treatments. Captopril administered daily to mice via intraperitoneal injection $(750 \mathrm{mg} / \mathrm{kg}$; at a volume of $0.3 \mathrm{ml}$ ) dramatically decreased the number and size of liver metastases from colorectal cancer [50,51]. Likewise, high daily doses of ACE inhibitors significantly reduced the risk of overall esophageal cancer (adenocarcinoma as well as squamous-cell cancer of the esophagus) by $45 \%$ $(\mathrm{OR}=0.55$; 95\% CI: $0.33-0.93)$ in a population-based case-control study nested within the General Practitioners' Research Database on individuals aged 40-84 years old from the UK during 1994-2001 [52].

Similar to ACE-2, TMPRSS2 is over-expressed in prostate adenocarcinoma, lung [53] and colorectal cancer, becoming an established tumour biomarker [37, 39, 54].

According to the Human Protein Atlas, ACE 2 and TMPRSS2 are highly expressed in prostate cancer and on tumor as well as normal colorectal epithelial tissues [36]. By contrast renal, urothelial, pancreatic and lung cancers showed low to moderate membranous or granular cytoplasmic immunoreactivity to the latter two proteins and their negative expression level was observed in other malignancies [48].

TMPRSS2 is capable of increasing the metastatic spread of prostate cancer by activating the Hepatocyte Growth Factor (HGF) [55]. TMPRSS2-ERG fusion in prostate tumors could be implicated in the activation of $\mathrm{NOTCH}$ pathway, capable of increasing proliferation and maintenance of progenitor cells. Chromatin immuneprecipitation and parallel sequencing showed that TMPRSS2-ERG was involved in the development of prostate cancer through disruption of lineage-specific differentiation and potentiation of the EZH2-mediated de-differentiation program [56]. Ectropic expression of TMPRSS2-ERG fusion was found to be not only involved in alteration of chemo-sensitivity, but also in chemo-responsiveness to androgens in prostate cancer, depending on cell line and fusion type [57]. Binding and expression change of the latter gene via SARS-CoV-2 could therefore be pursued as cancer treatment [48].

Since increased expression of TMPRSS2 stimulates androgen-driven prostate cancer progression, therapeutic approaches directed toward inhibition of TMPRSS2 have been suggested to reduce the risk of metastatic spread in patients with prostate cancer [55]. The transcription of TMPRSS2 and ACE2 in major organs could be modulated by systemic androgen deprivation among adult male mice, prompting camostat mesylate and androgen regulation as a therapeutic strategy for cancer patients infected by SARS-CoV-2 [58].

Among 9280 patients with confirmed SARS-CoV-2 infection from 68 hospitals of the Veneto Region (NorthEastern Italy), those affected by prostate cancer and not receiving androgen-deprivation therapy were significantly more susceptible to COVID- 19 (OR $=4.05$; 95\%CI: $1.55-10.59)$ than those receiving androgen deprivation (which decreases TMPRSS2 expression) [59].

\section{Expression of ACE- 2 in gastrointestinal malignancies}

Over-expression of ACE-2 and TMPRSS2 in tumor tissues may render them more vulnerable to SARSCoV-2 infection [42, 55]. According to data from TCGA and Genotype-Tissue Expression (GTE), ACE2 and TMPRSS2 were found to be potentially implicated in

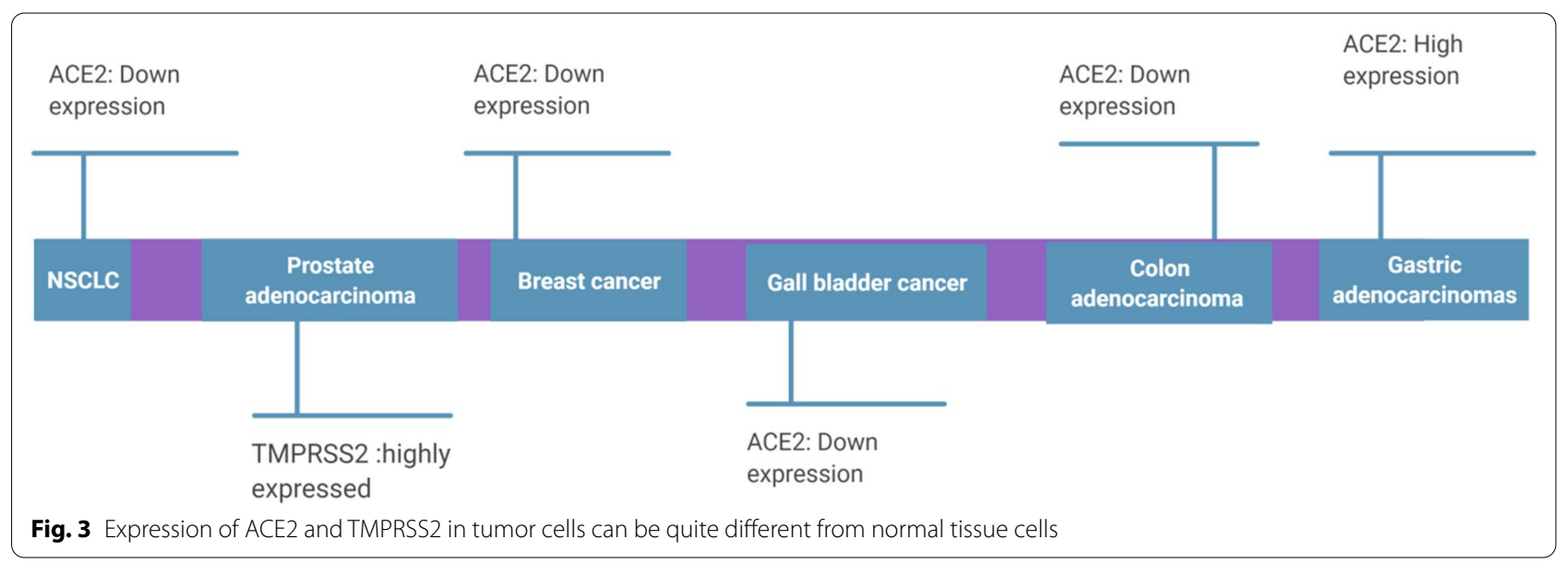


the genetic susceptibility to SARS-COV-2 among cancer patients [60].

In GI organs, the interaction of SARS-CoV-2 with ACE-2 results in more damage to the mucous membrane barrier and subsequent inflammatory cytokine response [61]. It has been suggested that the ACE-2 receptor could even be used by SARS-CoV-2 to enter cholangiocytes, inflicting direct damage to these cells [62].

The COVID-19 pandemic requires special attention on patients affected by GI tumors-malignancies more common in the elderly-who already have higher ACE-2 and TMPRSS2 expression and are more likely to be affected by other comorbidities that make them more susceptible to severe forms of COVID-19 [63]. There is evidence that ACE-2 expression upregulated in a wide variety of adenocarcinomas, including GI tract's carcinoma. Bernardi et al. observed that MasR and ACE-2 expression/activity were both upregulated in colon adenocarcinoma cells as compared to controls $(\mathrm{p}<0.001)$ or non-neoplastic colon mucosa resected $5 \mathrm{~cm}$ from tumour borders $(\mathrm{p}<0.005)$ [64].

It is also argued that the expression of ACE-2 increases with malignancy grade, being higher in adenocarcinoma than adenoma of the colon. Growing expression level of ACE2 has been reported from healthy individuals to patients affected by adenoma or colorectal cancer, who were more likely to be infected by SARS-CoV-2 than the former at analysis of ACE-2 RNA expression in a cohort study and other databases, implying intestinal tropism of SARS-CoV-2 [65].

This progressive upregulation was also observed for the stomach, where ACE-2 expression increases from gastritis to metaplasia and gastric adenocarcinomas [61].

As already mentioned, a higher risk of SARS-CoV-2 infection involves cancer patients, where a gradual increase of ACE-2 expression was found at Bulk tissue RNA sequencing and single-cell RNA sequencing of public data [61].

Among 52 pre/asymptomatic COVID-19 patients affected also by GI cancer at hospital admission-median age of 62.5 years-higher expression of ACE-2 was confirmed by immunofluorescence as compared with the general population. ACE2 was found to be remarkably expressed in enterocytes or macrophages of the appendix, rectum and colon, and the mortality rate was reported to be higher in COVID-19 patients (16.7\%) than COVID-19 free patients' (2.2\%) [66]. Higher expression of ACE-2 may therefore influence the risk of GI tract tumors. Different types of cytokines are produced by $\mathrm{T}$ helper cells against infectious diseases [67]. Long-term chronic conditions may contribute to malignant changes of the GI mucosa mediated by cytokines, and severe
COVID-19 is frequently associated with cytokine storm syndrome [61].

The exact underlying mechanism for the upregulation of ACE-2 in GI adenoma and carcinoma is still unknown and several potential explanatory mechanisms have been suggested, including local inflammation in metaplasia [61], since expression of ACE-2 and TMPRSS2 were found to be enhanced in the rectum of patients with inflammatory bowel disease [68]. Nevertheless, ACE2 and TMPRSS2 expression sustained by inflammatory bowel disease is seemingly region-specific across the entire intestine, being found to be reduced in the inflamed ileum [68].

Dysbiosis has been linked with several diseases [6971], including GI cancers, local inflammation due to malignant transformations, and chemotherapy [72-74]. Recent studies have suggested that dysbiosis can increase the mortality risk of COVID-19 patients, by altering the ACE-2 pathway [75]. It has been described that the complex of ACE-2 combined with sodium-dependent neutral amino acid transporter (B(0)AT1) can influence the regulation of GI flora [75]. In addition, an in vivo study by Costa et al. revealed USF1 gene expression as a new central regulator of DNA damage against helicobacter pylori $(\mathrm{Hp})$ infection and this gene is associated with patient prognosis in gastric cancer [76].

\section{ACE-2 and TMPRSS2 polymorphisms}

TMPRSS2 is expressed in Type II alveolar cells, alveolar macrophages and bronchial epithelial cells, whereas it is not expressed by Type I alveolar cells [77]. Single nucleotide polymorphisms (SNPs) are involved in overexpression of TMPRSS2 [78]. Since the lung is one of the primary target locations of SARS-CoV-2, it is argued that TMPRSS2 expression levels in pulmonary cells change across different populations, with consequent variable susceptibility to COVID-19.

In a German case control study on 239 positive and 253 negative SARS-CoV-2 patients recruited from 11 March-31 October 2020. The TMPRSS2 rs383510 variant was significantly associated with enhanced risk of SARSCoV-2 infection (OR $=2.00$; 95\%CI: $1.30-3.08 ; \mathrm{p}=0.002)$. In a second multivariable model, male sex was the sole independent predictor $[\mathrm{OR}=2.64 ; 95 \% \mathrm{CI}$ 1.44-4.84; $\mathrm{p}=0.002)$ of COVID-19 severity [79]. Nevertheless, the role of TMPRSS2 gene polymorphism on SARS-CoV-2 risk requires further confirmatory evidence on larger studies and different populations [79].

ACE-2 polymorphisms have been associated with several co-morbidities, including malignancies, essential hypertension (G8790A polymorphism) and cerebrovascular accidents in patients affected by type 2 diabetes 
mellitus. Exomics analysis in native and mixed South American populations and silico genomics databank assessment of other populations revealed extensive ACE2 polymorphisms, which could have an impact on clinical manifestations and outcomes of COVID-19 [80]. In particular, ACE-2 polymorphism could be linked to multiorgan failures in COVID-19 patients [81] and may cause mild to severe forms of the disease in certain groups [82], influencing the respective prevalence and mortality rate [83]. The log-transformed prevalence $\left(R^{2}=0.410\right.$; $\mathrm{p}<0.0001)$ and mortality $\left(\mathrm{R}^{2}=0.457 ; \mathrm{p}<0.0001\right)$ for COVID-19 in 33 countries (on April 1, 2020) negatively correlated with ACE-1 D allele frequency, taking into account the start of the epidemic in each country [83].

ACE-2 I/D polymorphism, which has been found to be associated with comorbidities such as diabetes and hypertension, is suspected to be a causal factor in severe forms of COVID-19 [84, 85]. In a genetic study on 64 Egyptian patients, 40 with hypertension and 24 with type 2 diabetes, the $D D$ allele of ACE gene was associated with increased risk of hypertension and/or diabetes than DI allele $(\mathrm{OR}=3.00 ; 95 \% \mathrm{Cl} 0.993-9.067)$ and II allele $(\mathrm{OR}=4.250$; 95\% CI 1.234-14.630a) [85]. Conversely, the $\mathrm{D}$ allele was associated with increased risk of hypertension $(\mathrm{OR}=3.13 ; 95 \% \mathrm{Cl}: 1.405-6.978)$ and diabetes $(\mathrm{OR}=4.14 ; 95 \% \mathrm{CI}: 1.615-10.622)$ than the I allele [85].

Analyzing 349 worldwide population samples from Allele Frequency Database (ALFRED), ID and DD ACE polymorphisms were found to be associated with enhanced ACE/Ang-II activity, increased blood pressure and severe acute respiratory distress syndrome among COVID-19 patients as compared with other genotypes [86] As already mentioned, ACE-2 polymorphism can be more common in some GI cancers and can also promote malignant mutations. For instance, in a Chinese study contrasting 241 colorectal cancer patients with 299 non-cancer controls enrolled from April 2008 to October 2010, those carrying the ACE D allele were more likely to develop undifferentiated tumors $(\mathrm{OR}=1.54 ; 95 \% \mathrm{CI}$ : 1.04-2.28) and metastasis (OR=1.56; 95\%CI: $1.08-2.26$ ) as compared to those carrying the ACE I genotype, although there was no remarkable correlation among cases and controls [87].

In a study comparing 113 gastric cancer patients (24 with the ACE II allele and 32 with the DD genotye) and 189 controls with no gastric cancer, a significantly higher number of lymph node metastases $(\mathrm{p}<0.001)$ and higher Unio Internationale Contra Cancrum (UICC) tumor stage $(p=0.01)$ were associated with the DD genotype as compared with the II allele. Furthermore, ACE was expressed by endothelial cells in $100 \%$ collected specimens of gastric cancer at immunohistochemistry [88].
Although no association between $\mathrm{H}$. pylori positivity or stomach atrophy and ACE polymorphism was found in a Japanese study on 202 gastric cancer patients and 454 healthy controls, the risk of gastric cancer was significantly higher among patients with I/D genotype affected by atrophic gastritis caused by Helicobacter pylori (OR=1.59; 95\%CI: 1.02-2.48) [89]. A German study compared the genomic DNA from 88 patients with early gastric cancer confined either to the mucosa or submucosa with 145 non-cancer controls. II ACE genotype featured by low activity $(\mathrm{OR}=0.20$; $95 \% \mathrm{CI}$ : 0.08 $0.54 ; \mathrm{p}=0.009)$ and ID/II with intermediate/low activity $(\mathrm{OR}=0.55 ; 95 \% \mathrm{CI}: 0.31-0.96 ; \mathrm{p}=0.044)$ were significantly less expressed than the reference (DD allele with high activity) [90].

Combining all the above evidence, ACE I/D polymorphism may play different roles, depending on the type of cancer. There is a possibility that specific ACE-2 polymorphisms, more common in patients with GI cancers, may make these patients more susceptible to severe forms of COVID-19 and related adverse outcomes such as multi-organ failure. Furthermore, some similarities between signaling cellular pathways in GI malignant transformations and COVID-19 may arguably exist.

\section{Suspension of gastrointestinal cancer screening programs in COVID-19 pandemic}

In several countries, a sequential scheme for early diagnosis of colorectal cancer in adults older than 55 years has been deployed [91]. The COVID-19 pandemic interfered with many screening and prevention programs for GI cancers [92]. In March of 2020, the American Cancer Society suspended all cancer screening programs on average-risk individuals until further update, due to rising number of COVID-19 cases [93]. The latter restrictions were extended to colonoscopy, which is the prevalent screening approach against colorectal cancer in the USA [93]. In the UK the reduction of endoscopy procedures performed during the COVID-19 pandemic ranged from $84 \%$ in Wales to $88 \%$ in England as compared to before the pandemic [94]. Alternative strategies are being pursued to postponing the management of cancer patients and rearrange tumour treatment strategies [95]. Although the number of screening colonoscopies performed in Italy during lock down (March 9-May 4) significantly decreased compared to year 2019 , in a retrospective observational study the detection rate of colorectal cancer $(\mathrm{p}=0.002)$ and high-risk adenomas (p-0.001) by screening colonoscopies was significantly higher during the pandemic. This may suggest that the COVID-19 pandemic resulted in unnecessary health care delays and missed GI cancer cases [96]. It has been estimated that the cancer diagnostic delays due to the 
COVID-19 pandemic can result in a 15.3-16.6\% increase in mortality rates for colorectal in UK [97]. There is moderate evidence that a $30+$ days delayed resection of colorectal cancer is associated with lower survival [98]. With that in mind, screening programs should not completely cease during the COVID-19 pandemic, but rather continuing in COVID-19-free healthcare facilities.

\section{Conclusions}

Although COVID-19 already had an extensive and immediate impact on burdened healthcare systems, its long-term effect on mortality and morbidity of the respective patients are yet to be elucidated. As discussed above, patients with GI cancers can be more vulnerable to COVID-19 than the general population due to higher expression of ACE-2 and TMPRSS2, which can serve as entry route for SARS-CoV-2 into target cells. On one hand, postponing screening procedures can be considered a way of protecting the vulnerable groups against COVID-19, by limiting their exposures to SARS-CoV-2 in healthcare facilities. Nonetheless, postponing cancer screening programs can enhance the morbidity and mortality risk attributable to GI malignancies, rendering these patients also more susceptible to COVID-19, since ACE-2 expression in enterocytes progressively increases with malignancy stage.

Cancer patients are considered one of the most vulnerable populations for COVID-19. It is therefore essential to maintain tailored screening programs against GI cancers during the current pandemic.

Although several of the current COVID-19 vaccines did not include cancer patients in their clinical trials and data on side effects of these vaccines in cancer patients are still unavailable, it is recommended to prioritize these patients in the COVID-19 vaccination programs.

\section{Acknowledgements}

Not applicable.

\section{Authors' contributions}

SS, LC, MKH, NGH, SHZ, NKH, HRM, SF, MI, AG MJ, AJ and RA participated in the search, drafting and revising the manuscript. All authors contributed to writing the manuscript. All authors read and approved the final manuscript.

\section{Funding}

No.

\section{Availability of data and materials}

Not applicable.

\section{Declarations}

Ethics approval and consent to participate Not applicable.

\section{Consent for publication}

All authors consent to the publication of the manuscript.

\section{Competing interests}

The authors declare that they have no conflicts of interest.

\section{Author details}

${ }^{1}$ Shahid Beheshti University of Medical Sciences, Tehran, Iran. ${ }^{2}$ Public Health Department, Local Health Unit N.2 "Marca Trevigiana", 31100 Treviso, Italy. ${ }^{3}$ Human Genetics Research Center, Baqiyatallah University of Medical Sciences, Tehran, Iran. ${ }^{4}$ Hematology and Oncology Research Center, Tabriz University of Medical Sciences, Tabriz, Iran. ${ }^{5}$ JC School of Public Health and Primary Care, Chinese University of Hong Kong, Hong Kong, China. ${ }^{6}$ Department of Pediatrics, Iran University of Medical Sciences, Tehran, Iran. ${ }^{7}$ Department of Clinical Pathology, Faculty of Veterinary Medicine, University of Tehran, Tehran, Iran. ${ }^{8}$ Department of Parasite Vaccine Research and Production, Razi Vaccine and Serum Research Institute, Agriculture Research, Education and Extension Organization (AREEO), Karaj, Iran. ${ }^{9}$ Health Research Center, Baqiyatallah University of Medical Sciences, Tehran, Iran. ${ }^{10}$ Nephrology and Urology Research Center, Baqiyatallah University of Medical Sciences, Tehran, Iran. ${ }^{11}$ Abadan School of Medical Sciences, Abadan, Iran. ${ }^{12}$ Department of Neurosurgery, University Medical Center, Tüebingen, Germany.

Received: 2 May 2021 Accepted: 30 July 2021

Published online: 16 August 2021

\section{References}

1. World Health Organization. Novel Coronavirus (2019-nCoV) situation reports, released by the World Health Organization (WHO); 2020. https:// www.who.int/emergencies/diseases/novel-coronavirus-2019/situationreports. Accessed 2 May 2021.

2. Moghadas SM, Shoukat A, Fitzpatrick MC, Wells CR, Sah P, Pandey A, et al. Projecting hospital utilization during the COVID-19 outbreaks in the United States. Proc Natl Acad Sci USA. 2020;117(16):9122-6.

3. Soltany A, Hamouda M, Ghzawi A, Sharaqi A, Negida A, Soliman S, et al. A scoping review of the impact of COVID-19 pandemic on surgical practice. 2020. Ann Med Surg (Lond). 2020;57:24-36.

4. European Centre for Disease Prevention and Control. COVID-19 vaccination and prioritisation strategies in the EU/EEA; 2020. https://www.ecdc. europa.eu/sites/default/files/documents/COVID-19-vaccination-andprioritisation-strategies.pdf. Accessed 20 June 2021.

5. Yang J, Zheng W, Shi H, Yan X, Dong K, You Q, et al. Who should be prioritized for COVID-19 vaccination in China? A descriptive study. BMC Med. 2021;19(1):45.

6. Ng SC, Herbert Tilg H. COVID-19 and the gastrointestinal tract: more than meets the eye. Gut. 2020;69(6):973-94.

7. Tsatsakis A, Calina D, Falzone L, Petrakis D, Mitrut R, Siokas V, et al. SARS-CoV-2 pathophysiology and its clinical implications: an integrative overview of the pharmacotherapeutic management of COVID-19. Food Chem Toxicol. 2020;146:111769.

8. Cao C, Chen M, He L, Xie J, Chen XJCC. Clinical features and outcomes of COVID-19 patients with gastrointestinal symptoms. Crit Care. 2020;24(1):340.

9. Zhao Y, Cao Y, Wang S, Cai K, Xu K. COVID-19 and gastrointestinal symptoms. Br J Surg. 2020;107(10):e382-3.

10. Zhang N, Gong Y, Meng F, Bi Y, Yang P, Wang FJM. Virus shedding patterns in nasopharyngeal and fecal specimens of COVID-19 patients. Sci Chia Life Sci. 2021;64(3):486-8.

11. Ye Q, Wang B, Zhang T, Xu J, Shang S. The mechanism and treatment of gastrointestinal symptoms in patients with COVID-19. Am J Physiol Gastrointest Liver Physiol. 2020;319(2):G245-52.

12. Tian $Y$, Rong $L$, Nian $W$, He $Y$. Review article: gastrointestinal features in COVID-19 and the possibility of faecal transmission. Aliment Pharmacol Ther. 2020;51(9):843-51.

13. Hindson J. COVID-19: faecal-oral transmission? Nat Rev Gastroenterol Hepatol. 2020;17(5):259

14. Yang P, Gu H, Zhao Z, Wang W, Cao B, Lai C, et al. Angiotensin-converting enzyme 2 [ACE2) mediates influenza H7N9 virus-induced acute lung injury. Sci Rep. 2014;4:7027.

15. Han DP, Penn-Nicholson A, Cho MWJV. Identification of critical determinants on ACE2 for SARS-CoV entry and development of a potent entry inhibitor. Virology. 2006;350(1):15-25. 
16. Haga S, Yamamoto N, Nakai-Murakami C, Osawa Y, Tokunaga K, Sata T, et al. Modulation of TNF-a-converting enzyme by the spike protein of SARS-CoV and ACE2 induces TNF-a production and facilitates viral entry. Proc Natl Acad Sci USA. 2008;105(22):7809-14.

17. Pagliaro P, Penna C. ACE/ACE2 ratio: a key also in 2019 coronavirus disease (Covid-19)? Front Med (Lausanne). 2020;7:335.

18. Ge X-Y, Li J-L, Yang X-L, Chmura AA, Zhu G, Epstein JH, et al. Isolation and characterization of a bat SARS-like coronavirus that uses the ACE2 receptor. Nature. 2013:503(7477):535-8.

19. Zhang H, Penninger JM, Li Y, Zhong N, Slutsky AS. Angiotensin-converting enzyme 2 (ACE2) as a SARS-CoV-2 receptor: molecular mechanisms and potential therapeutic target. Intensive Care Med. 2020;46(4):586-90.

20. Hoffmann M, Kleine-Weber $\mathrm{H}$, Schroeder S, Krüger N, Herrler T, Erichsen S, Schiergens TS, Herrler G, Wu NH, Nitsche A, Müller MA, Drosten C, Pöhlmann S. SARS-CoV-2 cell entry depends on ACE2 and TMPRSS 2 and is blocked by a clinically proven protease inhibitor. Cell. 2020;181(2):27180.e8.

21. Taneera J, El-Huneidi W, Hamad M, Mohammed AK, Elaraby E, Hachim MY. Expression profile of SARS-CoV-2 host receptors in human pancreatic islets revealed upregulation of ACE2 in diabetic donors. Biol. 2020;9(8):215

22. Iwata-Yoshikawa N, Okamura T, Shimizu Y, Hasegawa H, Takeda M, Nagata N. TMPRSS2 contributes to virus spread and immunopathology in the airways of murine models after coronavirus infection. J Virol. 2019;93:e01815-8.

23. Glowacka I, Bertram S, Müller MA, Allen P, Soilleux E, Pfefferle S, et al. Evidence that TMPRSS2 activates the severe acute respiratory syndrome coronavirus spike protein for membrane fusion and reduces viral control by the humoral immune response. J Virol. 2011;85(9):4122-34.

24. Stopsack KH, Mucci LA, Antonarakis ES, Nelson PS, Kantoff PW. TMPRSS2 and COVID-19: serendipity or opportunity for intervention? Cancer Discov. 2020;10:779-82.

25. Zhang $H$, Kang Z, Gong H, Xu D, Wang J, Li Z, et al. Digestive system is a potential route of COVID-19: an analysis of single-cell co-expression pattern of key proteins in viral entry process. Gut. 2020;69:973-4.

26. Cegolon L, Pichierri J, Mastrangelo G, Cinquetti S, Sotgiu G, Bellizzi S, Pichierri G. Hypothesis to explain the severe form of COVID-19 in Northern Italy. BMJ Glob Health. 2020;5(6):e002564.

27. Oz M, Lorke DE. Multifunctional angiotensin converting enzyme 2, the SARS-CoV-2 entry receptor, and critical appraisal of its role in acute lung injury". Biomed Pharmacother. 2021;136:111193.

28. Bellavite PRenin-Angiotensin, System. SARS-CoV-2 and hypotheses about adverse effects following vaccination. EC Pharmacol Toxicol. 2021;9(4) ():01-10.

29. Wicik Z, Eyileten C, Jakubik D, Simões SN, Martins DC, Pavão R, et al. ACE2 interaction networks in COVID-19: a physiological framework for prediction of outcome in patients with cardiovascular risk factors. J Clin Med. 2020;9(11):3743.

30. Werion A, Belkhir L, Perrot M, Schmit G, Aydin S, Chen Z, et al. SARS-CoV-2 causes a specific dysfunction of the kidney proximal tubule. Kidney Int. 2020;98(5):1296-307.

31. Lukiw WJ, Pogue A, Hill JM. SARS-CoV-2 infectivity and neurological targets in the brain. Cell Mol Neurobiol. 2020. https://doi.org/10.1007/ s10571-020-00947-7.

32. Sun M, Yang J, Sun Y, Su GH. Inhibitors of RAS might be a good choice for the therapy of COVID-19 pneumonia. He He Hu Xi Za Zhi. 2020;43(3):219-22.

33. Ni W, Yang X, Yang D, Bao J, Li R, Xiao Y, et al. Role of angiotensin-converting enzyme 2 (ACE2) in COVID-19. Crit Care. 2020;24(1):422.

34. Khelfaoui H, Harkati D, Saleh BA. Molecular docking, molecular dynamics simulations and reactivity, studies on approved drugs library targeting ACE2 and SARS-CoV-2 binding with ACE2. J Biomol Struct Dyn. 2020. https://doi.org/10.1080/07391102.2020.1803967.

35. Singh $H$, Choudhari $R$, Nema V, Khan AA. ACE2 and TMPRSS2 polymorphisms in various diseases with special reference to its impact on COVID19 disease. Microb Pathog. 2021:150:104621.

36. Liu C, Wang K, Zhang M, Hu X, Hu T, Liu Y, et al. High expression of ACE2 and TMPRSS2 and clinical characteristics of COVID-19 in colorectal cancer patients. NPJ Precis Oncol. 2021;5(1):1.

37. Niu X, Zhu Z, Shao E, Bao J. ACE2 Is a prognostic biomarker and associated with immune infiltration in kidney renal clear cell carcinoma: implication for COVID-19. J Oncol. 2021. https://doi.org/10.1155/2021/ 8847307.

38. Wang XS. Angiotensin-converting enzyme 2 connects COVID-19 with cancer and cancer immunotherapy. World J Gastrointest Oncol. 2021;13(3):157-60.

39. Sanguedolce F, Cormio A, Brunelli M, D'Amuri A, Carrieri G, Bufo P, et al. Urine TMPRSS2: ERG fusion transcript as a biomarker for prostate cancer: literature review. Clin Genitoriurin Cancer. 2016;14(2):117-21.

40. Van Dam PA, Huizing M, Mestach G, Dierckxsens S, Tjalma W, Trinh XB, et al. SARS-CoV-2 and cancer: are they really partners in crime? Cancer Treat Rev. 2020;89:102068.

41. Peng L, Zagorac S, Stebbing J. Managing patients with cancer in the COVID-19 era. Eur J Cancer. 2020;132:5-7.

42. Yang J, Li H, Hu S, Zhou Y. ACE2 correlated with immune infiltration serves as a prognostic biomarker in endometrial carcinoma and renal papillary cell carcinoma: implication for COVID-19. Aging. 2020;12(8):6518-35.

43. Yang W, Li L, Zhang K, Ma K, Xie H, Gong Y, et al. ACE2 correlated with immune infiltration serves as a novel prognostic biomarker in clear cell renal cell carcinoma: implication for COVID-19. Int J Biol Sci. 2021:17:20-31.

44. Deshayes F, Nahmias C. Angiotensin receptors: a new role in cancer? Trends Endocrinol Metab. 2005;16(7):293-9.

45. Soto-Pantoja DR, Menon J, Gallagher PE, Tallant EA. Angiotensin-[1-7) inhibits tumor angiogenesis in human lung cancer xenografts with a reduction in vascular endothelial growth factor. Mol Ther. 2009;8(6):1676-83.

46. Krishnan B, Smith TL, Dubey P, Zapadka ME, Torti FM, Willingham MC, et al. Angiotensin-(1-7) attenuates metastatic prostate cancer and reduces osteoclastogenesis. Prostate. 2013;73(1):71-82.

47. Yu C, Tang W, Wang Y, Shen Q, Wang B, Cai C, et al. Downregulation of ACE2/Ang- [1-7)/Mas axis promotes breast cancer metastasis by enhancing store-operated calcium entry. Cancer Lett. 2016;376(2):268-77.

48. Li J, Yang Z-I, Ren X, Zou Q, Yuan Y, Liang L, et al. ACE2 and FZD1 are prognosis markers in squamous cell/adenosquamous carcinoma and adenocarcinoma of gallbladder. J Mol Hist. 2014;45:47-57.

49. Beyazit Y, Purnak T, Suvak B, Kurt M, Sayilir A, Turhan T, et al. Increased ACE in extrahepatic cholangiocarcinoma as a clue for activated RAS in biliary neoplasms. Clin Res Hepatol Gastroenterol. 2011;35(10):644-9.

50. Neo JH, Ager El, Angus PW, Zhu J, Herath CB, Christophi C. Changes in the renin angiotensin system during the development of colorectal cancer liver metastases. BMC Cancer. 2010;10:134.

51. Neo JH, Malcontenti-Wilson C, Muralidharan V, Christophi C. Effect of ACE inhibitors and angiotensin II receptor antagonists in a mouse model of colorectal cancer liver metastases. J Gastroenterol Hepatol. 2007;22:577-84.

52. Sjöberg T, García Rodríguez LA, Lindblad M. Angiotensin-converting enzyme inhibitors and risk of esophageal and gastric cancer: a nested case-control study. Clinical Gastroenterol Hepatol. 2007;5(10):1 160-6.e1.

53. Wang Q, Li L, Qu T, Li J, Wu L, Li K, et al. High expression of ACE2 and TMPRSS2 at the resection margin makes lung cancer survivors susceptible to SARS-CoV-2 with unfavorable prognosis. Front Oncol. 2021;11:644575.

54. Kong Q, Xiang Z, Wu Y, Gu Y, Guo J, Geng F. Analysis of the susceptibility of lung cancer patients to SARS-CoV-2 infection. Mol Cancer. 2020;19(1):80.

55. Lucas M, Heinlein C, Kim T, Hernandez, Malik MS, True LD, et al. The androgen-regulated protease TMPRSS2 activates a proteolytic cascade involving components of the tumor microenvironment and promotes prostate cancer metastasis. Cancer Discov. 2014;4:1310-25.

56. Yu J, Yu J, Mani RS, Cao Q, Brenner CJ, Cao X, et al. An integrated network of androgen receptor, polycomb, and TMPRSS2-ERG gene fusions in prostate cancer progression. Cancer Cell. 2010;17(5):443-54.

57. Swanson TA, Krueger SA, Galoforo S, Thibodeau BJ, Martinez AA, Wilson GD, et al. TMPRSS2/ERG fusion gene expression alters chemo- and radio-responsiveness in cell culture models of androgen independent prostate cancer. Prostate. 2011;71(14):1548-58.

58. Deng Q, Rasool RU, Russell RM, Natesan R, Asangani IA. Targeting androgen regulation of TMPRSS2 and ACE2 as a therapeutic strategy to combat COVID-19. iscience. 2021;24(3):102254.

59. Montopoli M, Zumerle S, Vettor R, Rugge M, Zorzi A, Catapano MCV, et al. Androgen-deprivation therapies for prostate cancer and risk of 
infection by SARS-CoV-2: a population-based study $(n=4532)$. Ann Oncol. 2020;31(8):1040-5.

60. Ravaioli S, Tebaldi M, Fonzi E, Angeli D, Mazza M, Nicolini F, et al. ACE2 and TMPRSS2 potential involvement in genetic susceptibility to SARSCOV-2 in cancer patients. Cell Transp. 2020;29:963689720968749.

61. Xu J, Chu M, Zhong F, Tan X, Tang G, Mai J, et al. Digestive symptoms of COVID-19 and expression of ACE2 in digestive tract organs. Cell Death Discov. 2020;6:76.

62. Zhao B, Ni C, Gao R, Wang Y, Yang L, Wei J, et al. Recapitulation of SARSCoV-2 infection and cholangiocyte damage with human liver ductal organoids. Protein Cell. 2020;11(10):771-5.

63. Gosain R, Abdou Y, Singh A, Rana N, Puzanov I, Ernstoff MSJCOR. COVID-19 and cancer: a comprehensive review. Curr Oncol Rep. 2020;22(5):53.

64. Bernardi S, Zennaro C, Palmisano S, Velkoska E, Sabato N, Toffoli B, et al. Characterization and significance of ACE2 and Mas receptor in human colon adenocarcinoma. Nin Angiotensin Aldosterone Syst. 2012;13(1):202-9.

65. Chen $\mathrm{H}$, et al. Profiling ACE2 expression in colon tissue of healthy adults and colorectal cancer patients by single-cell transcriptome analysis. MedRxiv. 2020. https://doi.org/10.1101/2020.02.15.20023457.

66. Liu YL, Ren J, Yuan JP, Zhang ZJ, Guo WY, Guan Y, et al. Postoperative onset and detection of SARS-CoV-2 in surgically resected specimens from gastrointestinal cancer patients with pre/asymptomatic COVID19. Ann Surg. 2020;272(6):e321-8

67. Capitani N, Codolo G, Vallese F, Minervini G, Grassi A, Cianchi F, et al. The lipoprotein HP1454 of Helicobacter pylori regulates T-cell response by shaping T-cell receptor signalling. Cell Microbiol. 2019;21(5):e13006.

68. Suárez-Fariñas M, Tokuyama M, Wei G, Huang R, Livanos A, Jha D, et al. Intestinal inflammation modulates the expression of ACE2 and TMPRSS2 and potentially overlaps with the pathogenesis of SARS-CoV2-related disease. Gastroenterol. 2021;160(1):287-301.e20.

69. Aron-Wisnewsky J, Prifti E, Belda E, Ichou F, Kayser BD, Dao MC, et al. Major microbiota dysbiosis in severe obesity: fate after bariatric surgery. Gut. 2019;68(1):70-82.

70. Wang L, Alammar N, Singh R, Nanavati J, Song Y, Chaudhary R, et al. Gut microbial dysbiosis in the irritable bowel syndrome: a systematic review and meta-analysis of case-control studies. J Acad Nutr Diet. 2020;120(4):565-86.

71. Lippert K, Kedenko L, Antonielli L, Kedenko I, Gemeier C, Leitner M, et al. Gut microbiota dysbiosis associated with glucose metabolism disorders and the metabolic syndrome in older adults. Benef Microb. 2017;8(4):545-56.

72. Montassier E, Gastinne T, Vangay P, Al-Ghalith G, Bruley des Varannes S, Massart S, et al. Chemotherapy-driven dysbiosis in the intestinal microbiome. Pharmacol Ther. 2015:42(5):515-28.

73. Le Bastard Q, Ward T, Sidiropoulos D, Hillmann BM, Chun CL, Sadowsky $\mathrm{MJ}$, et al. Fecal microbiota transplantation reverses antibiotic and chemotherapy-induced gut dysbiosis in mice. Rep. 2018;8(1):6219.

74. Tsuei J, Chau T, Mills D, Wan YJ. Bile acid dysregulation, gut dysbiosis, and gastrointestinal cancer. Exp Biol Med (Maywood). 2014;239(11):1489-504.

75. Viana SD, Nunes S, Reis F. ACE2 imbalance as a key player for the poor outcomes in COVID-19 patients with age-related comorbidities-role of gut microbiota dysbiosis. Ageing Res Rev. 2020;62:101123.

76. Costa L, Corre S, Michel V, Le Luel K, Fernandes J, Ziveri J, et al. USF1 defect drives p53 degradation during Helicobacter pylori infection and accelerates gastric carcinogenesis. Gut. 2020;69(9):1582-91.

77. Bertram S, Heurich A, Lavender H, Gierer S, Danisch S, Perin P, Lucas JM, Nelson PS, PöhImann S, Soilleux EJ. Influenza and SARS-coronavirus activating proteases TMPRSS2 and HAT are expressed at multiple sites in human respiratory and gastrointestinal tracts. PLoS ONE. 2012;7(4):e35876.

78. Cheng Z, Zhou J, To KK, Chu H, Li C, Wang D, et al. Identification of TMPRSS2 as a Susceptibility Gene for Severe 2009 Pandemic A(H1N1) Influenza and A(H7N9) Influenza. J Infect Dis. 2015;212(8):1214-21.

79. Schönfelder K, Breuckmann K, Elsner C, Dittmer U, Fistera D, Herbstreit $F$, et al. Transmembrane serine protease 2 polymorphisms and susceptibility to severe acute respiratory syndrome coronavirus type 2 infection: a German case-control study. Front Genet. 2021;12:667231.
80. Khayat AS, de Assumpção PP, Meireles Khayat BC, Thomaz Araújo TM, Batista-Gomes JA, Imbiriba LC, et al. ACE2 polymorphisms as potential players in COVID-19 outcome. PLoS ONE. 2020;15(12):e0243887.

81. Bosso M, Thanaraj TA, Abu-Farha M, Alanbaei M, Abubaker J, Al-Mulla FJMT-M, et al. The two faces of ACE2: the role of ACE2 receptor and its polymorphisms in hypertension and COVID-19. Mol Ther Methods Clin Dev. 2020;18:321-7.

82. Devaux CA, Rolain J-M, Raoult D, Immunology. Infection. ACE2 receptor polymorphism: Susceptibility to SARS-CoV-2, hypertension, multi-organ failure, and COVID-19 disease outcome. Immunol Infect. 2020;53(3):425-35.

83. Delanghe JR, Speeckaert MM, De Buyzere ML. COVID-19 infections are also affected by human ACE1 D/I polymorphism. Clin Chem Lab Med. 2020;58(7):1125-6.

84. Singh $H$, Choudhari R, Nema V, Khan AA. ACE2 and TMPRSS2 polymorphisms in various diseases with special reference to its impact on COVID-19 disease. Microb Pathog. 2021;150:104621.

85. Zarouk WA, Hussein IR, Esmaeil NN, Raslan HM, Reheim HAA, Moguib $\mathrm{O}$, et al. Association of angiotensin converting enzyme gene (I/D) polymorphism with hypertension and type 2 diabetes. Bratisl Lek Listy. 2012;113(1):14-8

86. Sarangarajan R, Winn R, Kiebish MA, Bountra C, Granger E, Narain NR. Ethnic prevalence of angiotensin-converting enzyme deletion (D) polymorphism and COVID-19 risk: rationale for use of angiotensinconverting enzyme inhibitors/angiotensin receptor blockers. J Racial Ethn Health Disparities. 2020;8:1-8.

87. Liu S-Y, Sima X, Wang C-H, Gao M. The association between ACE polymorphism and risk of colorectal cancer in a Chinese population. Clin Biochem. 2011:44(14-15):1223-6.

88. Rocken C, Lendeckel U, Dierkes J, et al. The number of lymph node metastases in gastric cancer correlates with the angiotensin I-converting enzyme gene insertion/deletion polymorphism. Clin Cancer Res. 2005:11:2526-30.

89. Goto Y, Ando T, Nishio K, et al. The ACE gene polymorphism is associated with the incidence of gastric cancer among $\mathrm{H}$. pylori seropositive subjects with atrophic gastritis. Asian Pac J Cancer Prev. 2005;6:464-7.

90. Ebert MP, Lendeckel U, Westphal S, et al. The angiotensin I-converting enzyme gene insertion/deletion polymorphism is linked to early gastric cancer. Cancer Epidemiol Biomark Prev. 2005;14:2987-9.

91. Schreuders EH, Ruco A, Rabeneck L, Schoen RE, Sung JJ, Young GP, Kuipers EJ. Colorectal cancer screening: a global overview of existing programmes. Gut. 2015;64(10):1637-49.

92. Del Vecchio Blanco G, Calabrese E, Biancone L, Monteleone G, Paoluzi OAP. The impact of COVID-19 pandemic in the colorectal cancer prevention. Int J Colorectal Dis. 2020;35:1-4.

93. Shaukat A, Church T. Colorectal cancer screening in the USA in the wake of COVID-19. Lancet Gastroenterol Hepatol. 2020;5(8):726-7.

94. Rutter MD, Brookes M, Lee TJ, Rogers P, Sharp LJG. Impact of the COVID-19 pandemic on UK endoscopic activity and cancer detection: a National Endoscopy Database Analysis. Gut. 2021;70:537-43.

95. Di Fiore F, Bouché O, Lepage C, Sefrioui D, Gangloff A, Schwarz L, et al. COVID-19 epidemic: Proposed alternatives in the management of digestive cancers: a French intergroup clinical point of view [SNFGE, FFCD, GERCOR, UNICANCER, SFCD, SFED, SFRO, SFR). Dig Liver Dis. 2020;52(6):597-603.

96. D'Ovidio V, Lucidi C, Bruno G, Lisi D, Miglioresi L, Bazuro MEJCCC. Impact of COVID-19 pandemic on colorectal cancer screening program. Colorectal Cancer. 2021;20(1):e5-11.

97. Maringe C, Spicer J, Morris M, Purushotham A, Nolte E, Sullivan R, et al. The impact of the COVID-19 pandemic on cancer deaths due to delays in diagnosis in England, UK: a national, population-based, modelling study. Lancet Oncol. 2020;21(8):1023-34.

98. Fligor SC, Wang S, Allar BG, Tsikis ST, Ore AS, Whitlock AE, et al. Gastrointestinal malignancies and the COVID-19 pandemic: evidence-based triage to surgery. Gastrointest Surg. 2020;24(11):2698-9.

\section{Publisher's Note}

Springer Nature remains neutral with regard to jurisdictional claims in published maps and institutional affiliations. 